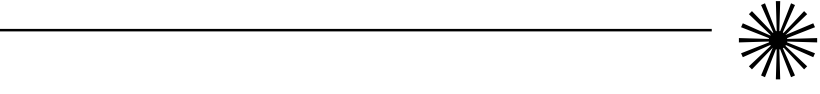

\title{
A CONSTRUÇÃO DE UM TERRITÓRIO RELIGIOSO MÓVEL NO BRASIL: ISLAM, IDENTIDADES E SIMBOLISMO.
}

- KARINA ARROYO CRUZ GOMES DE MENESES ${ }^{1}$

RESUMO: NESTE ARTIGO FOI ANALISADO UM RITUAL RELIGIOSO ISLÂMICO COM PARTICULARIDADES RELEVANTES AO CAMPO DA CIÊNCIA GEOGRÁFICA. A INVESTIGAÇÃO PROCUROU COMPREENDER COMO O SAGRADO SE MANIFESTA EM SEU TERRITÓRIO, CONSIDERANDO A PARTICULARIDADE DO OBJETO DE PESQUISA. A PARTIR DO APROFUNDAMENTO CONCEITUAL EM TELA, AS PERSPECTIVAS ACERCA DA ACEPÇÃO DE TERRITÓRIO, APOIADAS EM UM EMBASAMENTO SÓCIO-ANTROPOLÓGICO, BUSCAM DESCREVER, ANALISAR E CLASSIFICAR, DENTRO DA GEOGRAFIA HUMANA, ESPECIFICAMENTE DA GEOGRAFIA CULTURAL RENOVADA, UMA PERFORMANCE RITUALÍSTICA CULTURAL E RELIGIOSA DE GRANDE EXPRESSIVIDADE DEMOGRÁFICA E AINDA POUCO DIVULGADA NO BRASIL. PORTANTO, O CONHECIMENTO DESTE RITUAL ISLÂMICO AGREGA, DE MANEIRA ABRANGENTE E OPORTUNA, NOVAS POSSIBILIDADES DE INTERPRETAR O LUGAR E O TERRITÓRIO, AMPLIANDO SEU SIGNIFICADO E PROPONDO NOVAS FORMAS DE APROPRIAÇÃO DOS CONCEITOS, E ADENTRANDO NA SUBJETIVIDADE COM A TERRITORIALIDADE MÓVEL ATRAVÉS DA TERRA IMAGINALIS.

PALAVRAS-CHAVE: TERRITÓRIO ISLÂMICO, RITUAL DE ASHURA, IDENTIDADE. 


\section{A espacialidade da celebração religiosa}

Para se compreender a religião islâmica na sua amplitude, é necessário, antes de tudo, que um olhar superficial permita perceber a enorme diversidade histórica, cultural e política do Islam contemporâneo. Para além da divisão política entre sunitas (cerca de $85 \%$ dos muçulmanos) e xiitas $(15 \%)$ existe uma gama de possibilidades de interpretar, praticar e vivenciar o Islam, tão multifacetado e plural, que coexiste nos diferentes grupos sociais e tradições culturais que compõe este mundo islâmico. Há países de maioria muçulmana em três continentes; Ásia, África e Oceania, percorrendo uma faixa que vai do Norte da África com o Marrocos e a Mauritânia no extremo ocidental, ao sudeste asiático, com a Indonésia no extremo oriental.

Apesar de o imaginário ocidental associar o Islam aos árabes do Oriente Médio, estes não representam a maioria demográfica do Islam.
Paquistão, por

Bangladesh, pela Índia e pelo Sri Lanka. O país com a maior população muçulmana é a Indonésia, onde cerca de $90 \%$ de seus 200 milhões de habitantes segue o Islam. Além disso, no correr do século $\mathrm{XX}$, importantes comunidades muçulmanas constituíram-se em boa parte dos países europeus e americanos. Existem entre 5 e 6 milhões nos EUA, 4 e 5 milhões na França, 3 milhões na Alemanha, 1,6 milhão no Reino Unido, 1 milhão na Espanha e 700.000 na Holanda. Na América do Sul existem comunidades muçulmanas expressivas. No Brasil cerca de 1 milhão, na Argentina entre 750.000 e 1 milhão e no Suriname, $20 \%$ da população.

(PINTO, 2010, p.23-24)

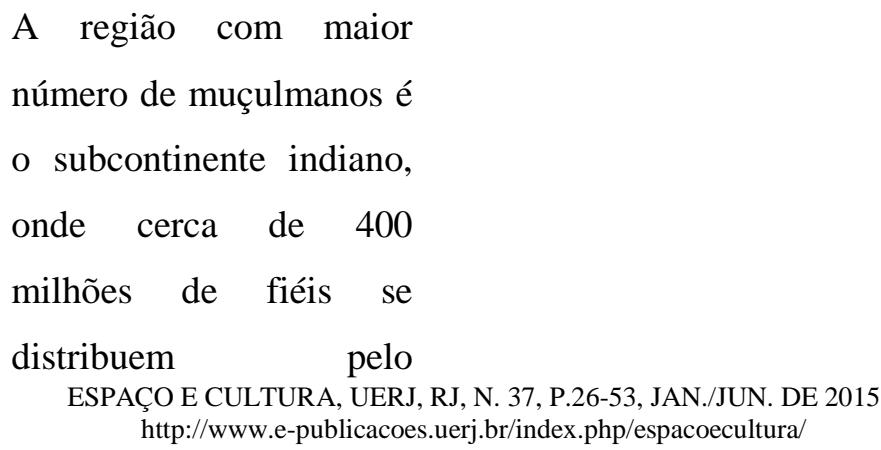


A essa pluralidade geográfica, étnica e cultural ainda se acrescentam variadas maneiras de interpretar leis, normas e comportamentos, por isso, a ideia de que a religião islâmica teria uma essência que pode ser reproduzida e reconhecida imediatamente é falsa. Mesmo nas performances ritualísticas há a necessidade de uma análise feita separadamente, já que o contexto cultural, a localidade e as práticas são fortemente influenciadas pelo lugar. Logo a legitimidade, a forma e o significado, além dos efeitos práticos de doutrinas, e rituais variam através das fronteiras culturais, de acordo com os diferentes grupos de uma mesma sociedade, e ainda, segundo as trajetórias individuais.

Portanto, a perspectiva desta abordagem, se encerra dentre os xiitas, objeto dessa análise. A partir desse ponto, o recorte do objetivo é ainda mais profundo, focando no ritual de celebração anual da Ashura. Existe uma enorme variedade de formas de celebração deste rito, no Líbano e no Iran, esse período cerimonial era tradicionalmente marcado por representações e recitações do drama de Karbala (ta'ziya) e grandes procissões, onde penitentes se auto-flagelam batendo as mãos no peito ou na cabeça (tatbir), ou ainda cortando a testa com facas e navalhas (latam) para que o sangue escorresse em sinal de luto. (Ibidem, p.26)

A República Islâmica do Iran favorece e promove suntuosas procissões, no entanto, proíbe o uso de objetos cortantes ou autoflagelantes, considerando o derramamento de sangue como uma superstição não-islâmica. Após a década de 90, por sua vez, temos no Líbano as celebrações utilizadas como palco de embates religiosos. Temos por um lado os seguidores de importantes clérigos xiitas do Sul do Líbano e do movimento xiita $\mathrm{AMAL}^{2}$ que consideram o uso de objetos cortantes, parte integral dos rituais de Ashura .

Já na pequena comunidade xiita duodecimena da Síria, o luto é expresso nos rituais apenas pelo choro sem mais nenhuma manifestação atrelada ao espetáculo. Por fim, se as cerimônias da Ashura no Oriente Médio possuem um tom de tristeza e penitência, já entre os muçulmanos caribenhos xiitas da Ilha de Trinidad y Tobago, a Ashura tornou-se uma celebração festiva (Ibidem, p. 27).

A cerimônia de Ashura é a encenação da Tragédia de Karbala (Iraque) em 661 d.C, que revive o luto e o martírio do Imam Hussein, neto de Muhammad (Maomé) fundador da religião islâmica. Seu martírio representa uma luta divina entre o sagrado e o profano e a vitória eterna contra a tirania e a opressão da secularização. A vida de Hussein foi dedicada à combater o Califado Omíada, que havia se afastado dos princípios islâmicos. Acredita-se que a sucessão do Profeta Muhhammad foi predestinada, e que a partir de sua linhagem 
sucederiam-se 12 Imames, sendo o primeiro Ali ibn Abu Taleb.

Portanto, se faz uma distinção conceitual importante, tendo em vista a multiplicidade de conceitos que perpassam a Tragédia. A Batalha de Karbala, foi o combate derradeiro entre o Imam Hussein contra um governo despótico e antiislâmico ${ }^{3}$. O martírio ocorreu no último dia da Revolução, que durou dez dias. Hussein não aceitou submeter-se a uma legislação corrompida e profana. A Ashura, portanto, refere-se ao espaço-tempo que compõe os dez primeiros dias de Muharram, o primeiro mês do calendário islâmico.

Deve-se saber que a instituição do xiismo, que foi denominada pela primeira vez como "Xiat Ali", ou seja, "Xiismo de Ali", iniciou-se no tempo da profecia de Muhammad. Portanto, o aparecimento da missão e convocação islâmica, sua expansão e seu progresso, ocorreram durante os vinte e três anos, a contar do ano da Revelação (610 d. C). Neste tempo o xiismo ganhou forma espacial, função e poder.

Nestes primeiros momentos a diversidade entre sunitas e xiitas, não causou maior impacto interno nem gerou novas teorias ou interpretações capazes de ameaçar a unidade da $U m m a h^{4}$. Apenas no ano da Tragédia, a Ummah viu a primeira grande cisão se concretizar indelevelmente, gerando novas perspectivas, comportamentos e até mesmo uma nova Jurisprudência foi fundamentada.

Este recorte temporal nos ajuda a compreender que o período até a Tragédia de Karbala e a consequente morte do Imam Hussein (681 d.C) foi representativa da expansão do Islam.

É nesse sentido que procuro salientar as diferenças entre as diversas formas do muçulmano xiita se expressar e compartilhar seu luto. Explicada as possibilidades de variação na interpretação e vivência da fé islâmica, acredito que pode-se partir pra um aprofundamento dos conceitos geográficos que sustentam a identidade social do grupo em questão.

\section{A Ashura em São Paulo: Migrações,} Rituais e Identidades

A cidade de São Paulo, que desde 1880 recebe imigrantes de origem libanesa xiita e hoje conta com mais de 1 milhão de descendentes é anualmente palco das representações de Ashura.

Num cenário mais crítico, a observação dos rituais e sua análise nos permitem a utilização de uma classificação profícua às ciências humanas, especialmente à Geografia Cultural Renovada, pós 70 , que se utiliza das classificações ritualísticas geográficosimbólicas para reordenar o espaço. Logo, ESPAÇO E CULTURA, UERJ, RJ, N. 37, P.26-53, JAN./JUN. DE 2015 http://www.e-publicacoes.uerj.br/index.php/espacoecultura/ 
este artigo nos permitirá encetar uma reflexão geográfica capaz de desvendar as apropriações culturais do espaço sagrado e as relações sociais mediadas por elementos simbólicos.

Embora não existam estatísticas confiáveis, uma vez que o censo brasileiro não permite $o$ registro de identidades étnicas, apenas de identidades raciais, as estimativas do número de árabes e seus descendentes no Brasil variam de três a dezesseis milhões de pessoas (PINTO, 2010, p.15), números altamente expressivos e capazes de configurar uma comunidade crescente capaz de reproduzir nos seus territórios culturais discursos e práticas específicas. Além disso, Oswaldo Truzzi (1997) oferece uma quantificação diferente que justifica em larga escala, a contabilização em número inferior ao proclamado por instituições oficiais. Ele afirma que até 1908 os imigrantes vindos do Oriente Médio eram classificados em "outras nacionalidades" e que, somente após essa data, eles apareceram como "turcos". Truzzi coloca o termo "libanês" em 1920 e o termo "sírio" em 1922. (Ibidem, p.49).

Uma análise dos modelos interpretativos e do universo discursivo da bibliografia sobre os árabes no Brasil revelou que tanto os estudos acadêmicos quanto os não acadêmicos seguem um fio condutor de ascensão e integração sistemáticos e lineares dos imigrantes na sociedade brasileira, onde o resultado final seria sua assimilação completa e irreversível, pelo abandono sistemático dos elementos culturais árabes. Esse modelo de assimilabilidade foi elaborado a partir do comprometimento das ciências sociais brasileira com a criação de uma "cultura nacional", homogênea e integradora dos diversos grupos sociais, tornando-se o quadro teórico dominante nos estudos sobre imigração e etnicidade realizados desde os anos de 1940 (Ibidem, p.17).

Portanto, essa visão de identidade étnica atrelada a objetos e conteúdos especificamente árabes já foi abandonada pelas ciências sociais e consequentemente para qualquer outro ramo da ciência que tenha seu aporte nos aspectos sociais inseridos em seu objeto de estudo, haja vista, o modelo teórico que representa a etnicidade como o resultado do processo de organização das diferenças culturais através de fronteiras simbólicas, é que de fato, exemplifica as configurações observadas entre os imigrantes árabes muçulmanos tanto de origem sunita como xiita. Os próprios grupos estão em constante fluxo de criatividade e diferenciação entre as gerações, e mesmo entre os indivíduos do mesmo grupo, haja vista, são as codificações dos geossímbolos e das expressividades cotidianas que reconfiguram continuamente as fronteiras exteriores e simbólicas, trazendo maior porosidade ou encrudescimento social. 
Na cidade de São Paulo, no bairro do Brás, em 1987 foi construída a Mesquita Muhammad Mensageiro de Deus, situada na rua Elisa Witacker, 17, Brás, e administrada pela Associação Religiosa Beneficente Islâmica do Brasil (ARBIB) ${ }^{5}$.
Imbuída do espírito de salvaguardar a tradição xiita, minoria nas migrações pós 1980, fundada por libaneses do sul, representa anualmente a Tragédia de Karbala através de dois elementos expressivos: ta'ziah e tatbir.

Mapa 1 - Bairro do Brás com localização da Mesquita (ARBIB)

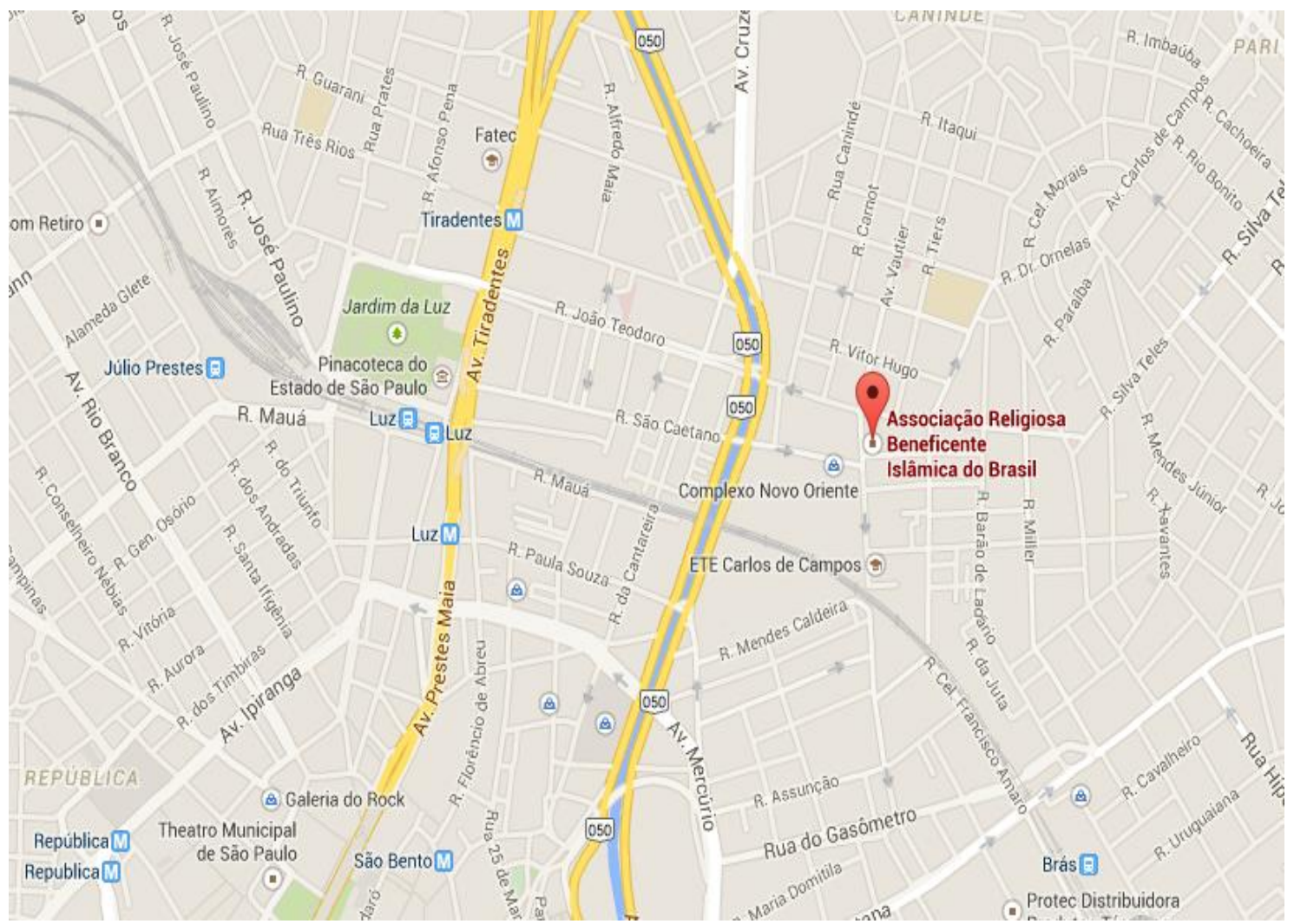

Fonte: http://goo.gl/J9F8od 
Estes elementos transcendem a materialidade dos símbolos presentes no ritual. A teatralização da Ashura traz a relação entre as estruturas expressivas e as estruturas sociais. As manifestações corporais e a invocação oral são expressões simbólicas que recriam o sentimento de luto, corroborando o pertencimento aos partidários de Ali. Tais elementos embora presentes em quase todas as celebrações de Ashura não devem ser considerados insígnias indispensáveis do espetáculo, em grande parte porque afirmar a existência de uma essência islâmica xiita a todas as celebrações seria demasiadamente simplista, devido a gama de puralidades de interpretações, experiências e vivências. O ritual de construção através da Topofilia, traz a terra imaginalis para uma materialidade real, permitindo à hierofania ser estabelecida. A história que embasa o espetáculo é determinante na emoção coletiva, no compartilhamento do luto, da tristeza e do sentimento de compaixão ao mártir Hussein. Recuperar os significados codificados na paisagem é condição sine qua non, conforme afirma Cosgrove (2012, p.220) para a interpretação das práticas sociais e, principalmente, reler os códigos na paisagem de Karbala, nos fornece toda uma cosmovisão que permite compreender a lógica do ritual de Ashura.

A Mesquita do Brás é uma forma simbólica grandiosa (CORRÊA, 2005), é a representação material de eventos e rituais religiosos passados que integram o meio ambiente construído, marcando a paisagem do bairro do Brás, determinando o espaço público de São Paulo. 
Figura 1 - Mesquita Muhammad Mensageiro de Deus no Brás, São Paulo.

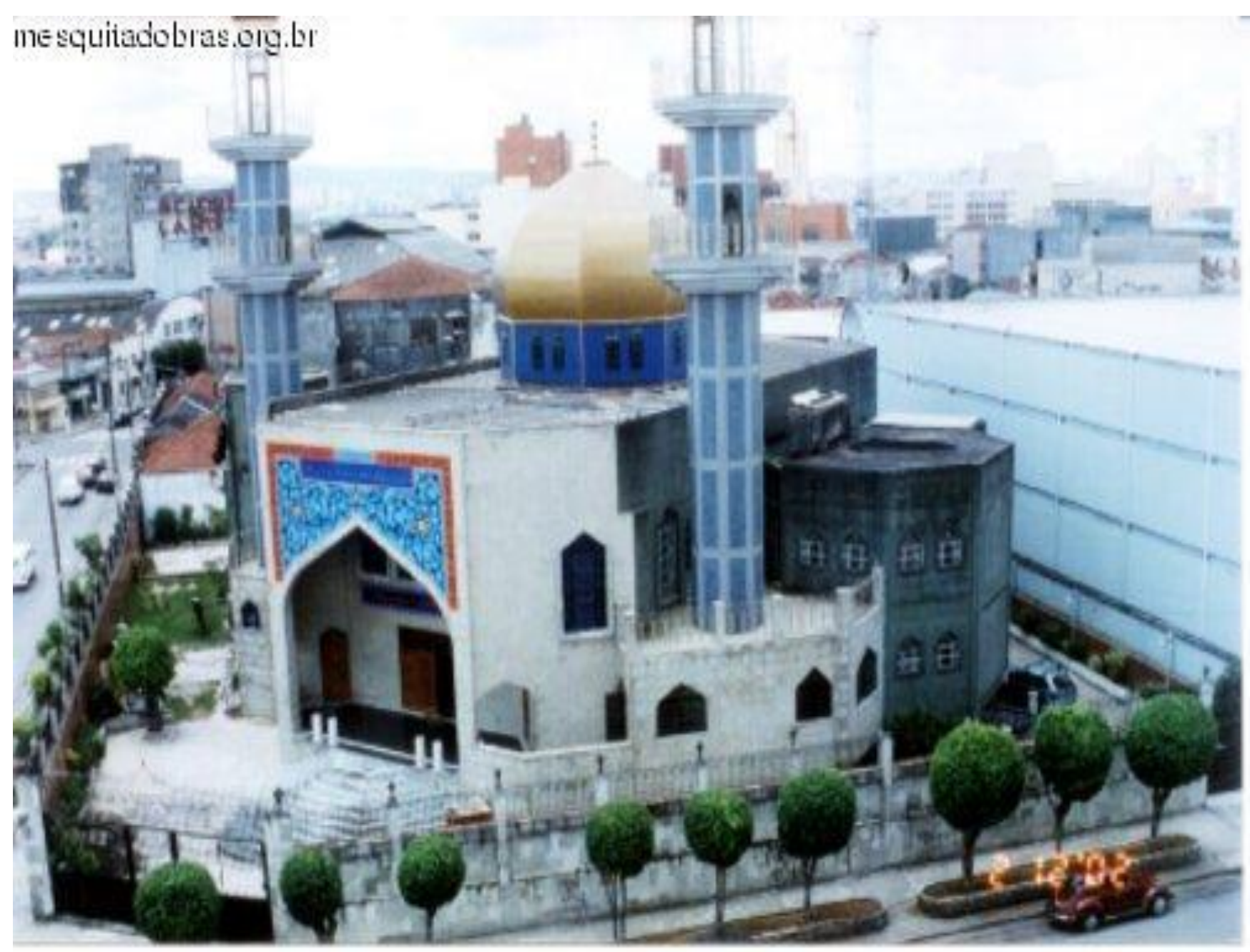

Fonte: http://goo.gl/MF8612 
De acordo com o autor, templos, inseridos na categoria de monumentos, são intencionalmente dotados de sentido político, comunicando mensagens associadas à celebração, contestação ou à memorialização, visando o presente e o futuro. Os monumentos, parafraseando Cosgrove (1998), estão em toda parte, impregnando a paisagem de símbolos, cujos significados podem ser variáveis, denotando celebração, memorialização e contestação (Ibidem). No caso da Mesquita, ela condensa um simbolismo que objetiva exatamente a memorialização de um ritual religioso, a celebração de uma vitória simbólica contra a tirania e a opressão dentro da historiografia islâmica e a contestação através da teatralização do luto da tragédia sofrida. Ela se impõe entre a morfologia homogênea das construções citadinas de perfil comercial, denota sua intencionalidade e finca indelevelmente sua presença através de sua arquitetura específica que confere identidade e poder. Os conflitos podem ser visíveis se aqui entendidos dentro de uma escala dimensional inserida no significado político pretendido por aqueles que a construíram. A natureza contrastante dos significados atribuídos a Mesquita por diferentes segmentos islâmicos imprime seu caráter fortemente político e passível de ser analisado por diferentes discursos. Para além da interpretação dos significados observáveis materialmente num primeiro momento, é importante destacar a finalidade mais importante da construção da Mesquita do Brás. Ali seria o protótipo ideal da terra de Karbala, por isso, faz-se necessário o entendimento da Tragédia que originou o rito para que assim se analise as dimensões do território e da identidade.

Após a morte do Imam, decapitado por seus inimigos, os sobreviventes da família foram arrastados como prisioneiros até Damasco na Síria. A irmã de Hussein, frente à Corte do Governador Mu'awiyah, profere um grande discurso, uma lamentação, ouvida por centenas de pessoas, que gera uma profunda comoção. Portanto, surge de Zainab Al-Kubra (irmã de Imam Hussein), a tradição anual da lembrança de Ashura, da lamentação, das elegias e da teatralização da dor e do sofrimento. Por isso, vemos que o primeiro Majlis ${ }^{6}$ realizado em memória do Imam Al Hussein foi o realizado em Damasco pelo irmão Ali ibnol Hussein e sua tia, Zainab Al-Kubra, juntamente com todas as mulheres e filhos dos Ahlul Bayt. Estes foram os únicos sobreviventes da Batalha, que tinham agora por missão, perpetuar a mensagem de Hussein e fazer desde evento uma lembrança eterna da identidade do povo xiita. Estes majlis foram realizados em todos os locais por onde passavam os sobreviventes, até chegar a Sham (Síria, sede do Governo) aonde Zainab Al-Kubra discursou perante o Governador . Na volta a Medinah também se reviveu a Batalha, 
explicando às populações locais o que ocorrera. As majlis encontraram seu ápice quarenta dias após a morte do Imam, quando todos retornaram a Karbala e reviveram a Ashura publicamente, em um espetáculo que atraiu grande parte do califado (Ibidem, p.167).

A esta celebração foi dado o nome de Arba'een (em árabe: quarenta. $\mathrm{Na}$ cultura árabe, o luto por falecimento de parentes dura quarenta dias) e lá foi erguido o Santo Santuário Imam Hussein atribuindo a cidade de Karbala o status de uma hierópolis islâmica xiita. Esta é uma das maiores peregrinações do mundo (MERVIN, 2000), e neste caso, assim como no Hajj, a peregrinação anual a Makah, um dos pilares do Islam, esse fluxo de peregrinos se dá através de uma periodicidade simbólica.

A partir de então as majlis de Ashura são anuais e quarenta dias depois, encerrando o período de luto, faz-se a peregrinação ao Santuário Imam Hussein.

Significados, história e memória compõem estes ciclos contínuos e necessários e são parte integrante do cosmos religioso, de acordo com Eliade:

“A significação profunda

de todos esses fatos parece ser a seguinte: para o homem religioso das culturas arcaicas, o Mundo renova -se anualmente, isto é, reencontra a cada novo ano a santidade original, tal como quando saiu das mãos do Criador"(1992, p.41).

De acordo com a tradição xiita, os Imames são indivíduos de uma Purificada Linhagem Profética, ilibados e infalíveis (TABATABAÍ, 2008). O Imamato é uma instituição religiosa, que exerce poder sobre os indivíduos, moldando-os às regras islâmicas e são fontes inesgotáveis de consultas e orientação. Portanto, o cumprimento de se observar o luto e tomar parte na preparação das majlis deixam de ser opcionais e não são somente um símbolo de fé, são condição de permanecer xiita e são, principalmente, uma reafirmação de identidade. Este vínculo se dá com a ligação de Hussein ao Profeta, e por continuidade, do muçulmano xiita com Karbala. É, sobretudo, a necessidade de ser agente na lembrança de um tempo sempre presente. “(...) Tempo também não é, para o homem religioso, nem homogêneo nem contínuo.” (ELIADE, 1992).

O valor simbólico da terra que martirizou o Imam representa a conexão com o Sagrado e a partir dessa evocação, todo um universo simbólico é necessário para sustentar a representação de uma realidade que se torna mais importante do que a realidade da paisagem religiosa. Vivenciar o luto e a reconstrução de 
Karbala se torna mais essencial do que estar em Karbala.

\section{A mobilidade da hierópolis islâmica}

A partir de uma análise geográfica, no que tange à origem das cidades, há duas vertentes interpretativas: a primeira delas nos aponta os antigos santuários paleolíticos como base inicial de desenvolvimento urbano. Se refere a uma abordagem que salienta e torna essencial a presença da religião (ROSENDAHL, 2009, p.15). É esta interpretação que fundamenta o origem das cidades-santuário, neste caso, especificamente, Karbala.Outros autores como Eliade (1962), Coulanges (1988), Mumford (1991) e Tuan (1980), compartilham dessas ideias (Ibidem, p.16). A outra vertente explicativa atribui às complexas transformações do neolítico o suporte da gênese e evolução das cidades.

Antes de um aprofundamento no conceito de hierópolis ou cidades-santuário, necessários na abordagem do simbolismo religioso e caráter sagrado ao espaço das cidades, cabe definir o conceito proposto por Rosendahl (1994);

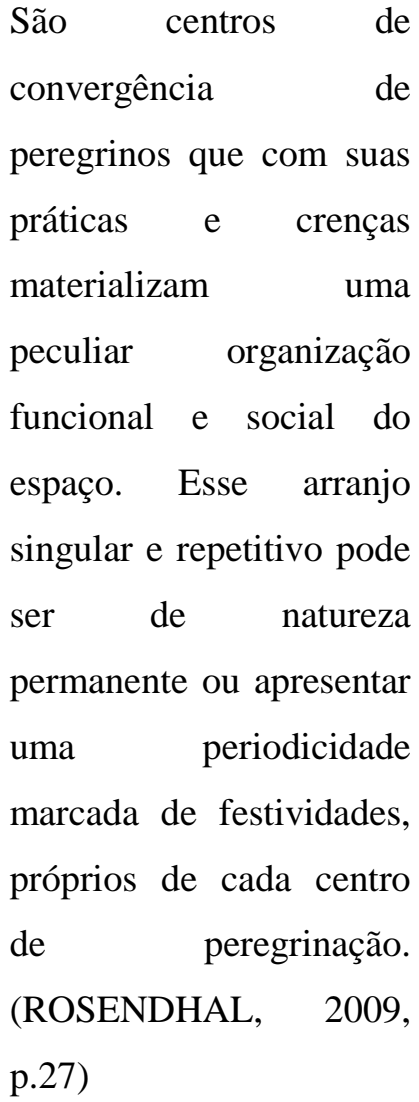

$\mathrm{Na}$ tentativa de associar o sagrado e o urbano, o templo aparece como conector fundamental e razão para que uma organização de cidadãos e serviços surja, concentrando diversas funções até ali dispersas e desorganizadas dentro de uma área limitada, originando as cidades. Portanto, cidade e religião, sob esta perspectiva são indissociáveis.

Ainda na interpretação da origem das cidades, consideram-se alguns fatores: técnica, política e religião (Ibidem, p. 19) . Neste caso, o aspecto religioso tem o poder transformador e sustentador daquela localidade e daquele ethos que deverá transformar-se na cidade-santuário. Para que essa ampliação do poder se consolide e se propague, é necessário que imagens e 
símbolos brotem ou sejam reavivados no inconsciente coletivo. Essa força adjacente, subjetiva e móvel é observada no Islam xiita como um fator de coesão e de identidade. De acordo com Rosendahl (2009),

"a cidade é erguida pela
vontade de Deus e o
sacerdote era o símbolo
todo-poderoso. Seria um
ser semi-divino, um
intermediário entre o céu
e a terra. O co-criador do
cosmo."

Sobre essa afirmação, se tratando da pesquisa aqui apresentada, algumas adaptações se fazem necessárias na formação e criação de Karbala.

Apesar dessa vontade divina embasar a criação da cidade de Karbala, como se pode ver na etimologia de seu nome : em hebraico Karb (fazenda) e Al (Deus) ${ }^{7}$, o sacerdócio de Imam Hussein é mais do que um símbolo de poder e de controle, ou seja, extravaza essa competência de intermediário entre $\mathrm{o}$ sagrado e o profano, que embora tenha um caráter semi-divino, á capaz de gerar em torno de sua História e tragédia uma normatização do tempo-espaço profano

Através dele e por força dele, a indumentária, a alimentação, os hábitos, as orações, e toda e qualquer ligação com o sagrado passam pelo intermédio e influência de Hussein. É uma liderança absoluta, normatizadora, que funda a essência da identidade islâmica xiita, e que apresenta um caráter reformista, de resgate em seu discurso. A ideia de territóriomatriz, desenvolvida neste estudo, como poderá ser lido neste artigo mais adiante, é um esforço de reinterpretação do conceito de território, mais bem adaptado ao objeto em análise, e que retoma essa questão.

Este sacerdócio, tenta ainda, resguardar e restaurar a identidade do Islam iniciado por Muhammad, que se perdeu ante aos califados seguintes, corruptos e que abandonaram a Shariah ${ }^{8}$ em detrimento de um poder temporal. Portanto, o neto do Profeta, Hussein, através do martírio em uma terra predestinada, suscitaria uma nova era e cadeia sucessória, culminando no Imamato Duodecimano.

Khazraji (2008) corrobora através de Rosendahl (2009) o caráter divino do surgimento das cidades sagradas, quando afirma que Muhammad em 626 d. C, ao pegar o neto Hussein ao colo, recebeu uma Revelação Divina - alcorânica- de que seu neto morreria em uma terra árida, martirizado e jovem. 


\section{O simbolismo da paisagem sagrada}

A partir do exposto, com vistas a uma maior compreensão da abrangência do simbólico, Bonnemaison (2005) vem ratificar a ideia de que os geossímbolos são capazes de criar um território; a terra de Karbala é então representada em pequena escala através da Turbah $^{9}$. Ela pode ser ainda mais incisiva quando de seu uso, em lembrar ao fiel quem ele é mantendo um vínculo cotidiano com o Sagrado. A geógrafa Corrêa, A.M. (2006) define geossímbolo como algo material ou como um ponto fixo que ali está para nos remeter a outro ponto, reificar uma ideia ou lugar diverso. Eles apontam para fora de si e marcam ausências. Portanto, representam o objeto guardando certa "ambiguidade", com um propósito bem definido.

\begin{abstract}
"Nesse sentido, o território móvel ou que é transposto realiza-se na produção de símbolos, que são portadores da vida em si mesmos".
\end{abstract} (Ibidem, 2006).

Portanto, a necessidade de territorializar pode ser constatada quando se observa a quantidade de elementos simbólicos necessários para os rituais cotidianos do xiita. As cinco orações diárias (Fajr, Zuhr, Asr, Maghreb, Ishá) são realizadas utilizando-se a turbah (figura 1) para a prostração (movimento ritual no qual o fiel de joelhos, se curva e encosta a fronte no chão em contemplação e submissão a Deus, também chamado movimento Sujud) 


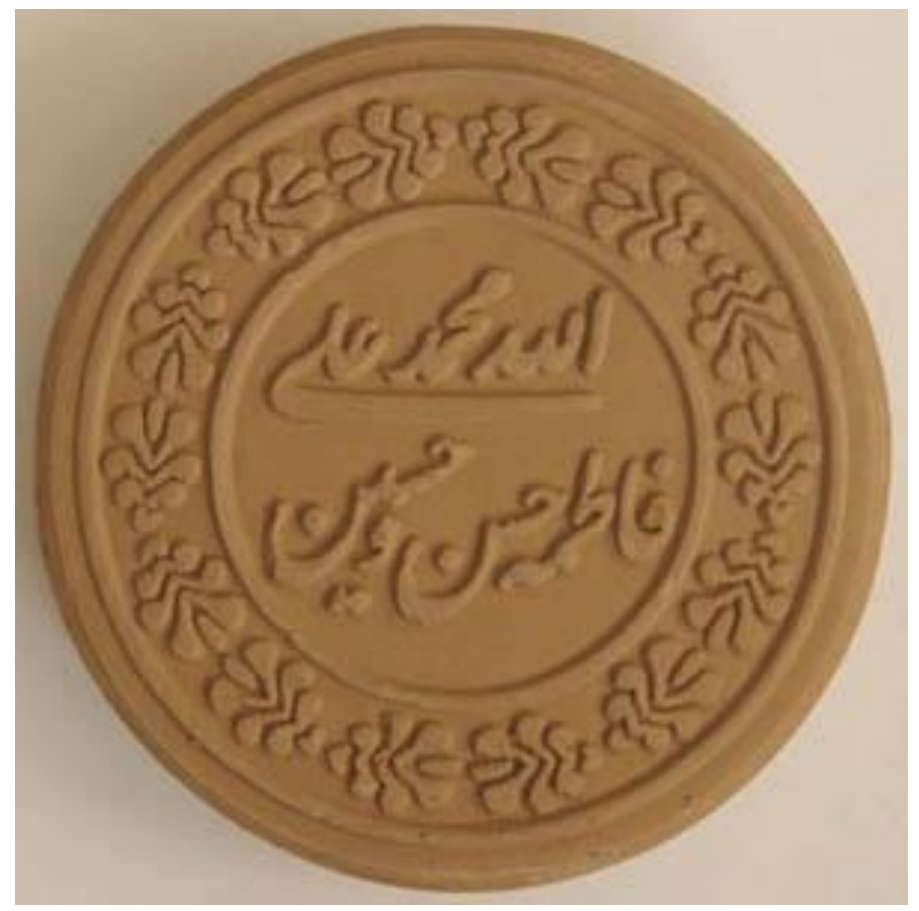

Fonte: http://goo.gl/c83bBW

Ao apoiar a fronte na turbah, o xiita relembra que aquele pequeno pedaço de terra, proveninete de Karbala está sendo o suporte para a ligação com o Sagrado, além disso, o sujud é o momento mais importante da performance (SCHETCHNER, 2006). Neste momento de entrega, de introspecção íntima, a única ligação com o mundo externo, agora amorfo e homogêneo é a sensação tátil com a terra de Karbala. A composição simbólica da cabeça representando a mente, a razão, a memória em consonância com a matéria, com a terra, configura uma territorialização per se, pois tona visível e palpável os traços identitários.

A imagem é um recurso da materialidade, ela tem presença forte no ritual da Ashura. As ideias e os discursos são complementados pela memória, pela imagem mental, a terra imaginalis que é evocada quando necessária, torna-se, assim, essencial. Permite a ela dar conta da polissemia do simbólico. Essa vertente abstrata traduz-se na transcendência.

É no sofrimento da dor que se firmam as identidades e finalmente, são erigidas fronteiras simbólicas. Portanto, a 
ideia de que um Imam, neto do Profeta e que inocente morreu martirizado sob penosas circunstâncias, gera uma sensação inacabada de que há uma Justiça Divina, piedosa e inquebrantável. No entanto, ela reverbera naqueles que se apiedam dessa Tragédia e reúnem sob uma forte comoção os seguidores de um Imam mártir e eterno. Nesse ínterim, a frase universal e eternizada por Ayatollah Seyyed Rouhollah Khomeini em seu exílio de que "Todo dia é Ashura, toda Terra é Karbala", confere um caráter universal e contínuo aos fatos e aos ritos. Exatamente por ser dita do exílio, tem forte apelo emocional e carga simbólica, conferindo a ideia de que a distância da terra sagrada não anula ou afasta a presença e a conexão com a terra.

\section{Lugar, Identidade e Território- matriz}

$$
\text { Partindo da universalidade }
$$
simbólica, tendo como princípio esta terra querida e sagrada, eternizada como um mapa mental, pode-se relembrar as considerações tuaninas (1883), que abordam a identidade enquanto conceito geográfico.

\author{
"Quase todos os grupos \\ humanos tendem a \\ considerar sua pátria \\ como centro do mundo" \\ (TUAN, 1983, p. 165).
}

Para que haja o conceito de pátria é necessário que haja uma localização e uma consciência coletiva de pertença àquele povo e àquele lugar.
Em diversas partes do
mundo esse sentido de
centralidade se torna
explícito por uma
concepção geométrica do
espaço orientada para os
pontos cardeais. O lar
está no centro de um
sistema espacial
astronomicamente
determinado. Um eixo
vertical, ligando o céu ao
mundo inferior, passa
pelo lar. As estrelas são
percebidas romo
movendo-se ao redor da
própria moradia; o lar é o
ponto focal de uma
estrutura cósmica

(TUAN, 1983, p. 165).

A centralidade ligada ao reconhecimento de um núcleo simbólico 
familiar foi abordado por Bonnemaison (In: CÔRREA，ROSENDAHL，2012，p.13), como espaço vivido em determinada territorialidade que emana da etnia, constituindo-se em relação cultural vivida entre dado grupo social e uma trama de lugares hierarquizados e interdependentes, originando um sistema espacial, isto é, um território. Ainda, segundo o autor, é pela existência de uma cultura que o território é criado; e é pelo território que uma cultura se fortalece, exprimindo-se a relação simbólica entre cultura e espaço. Outros geógrafos corroboram esta ideia e se apoiam em Cosgrove (1998) quando afirma que a geografia está em toda parte, exatamente pela possibilidade do homem semiografar os espaços, caracterizando-os através da atribuição de simbolismo. Norton (2000) reinterpreta o conceito de lugar elaborado por Tuan (1980) dando ênfase ao lugar como fenômeno inter-relativo, relacionado às identidades coletivas, o que pressupõe o sentido de lugar como passível de ser comunicado para outros, como algo legitimamente apropriado, moldável e flexível, construído por um grupo, fornecendo modelos de pertencimento em íntima relação entre o individual e o social. Os indivíduos estão em contínuo processo de interpretação, se decifram e são decifradas por seus códigos, pertencimentos e lugares construídos.
"A criação de lugares é um ato social, $e$, portanto, os lugares diferem porque assim as pessoas os construíram" (NORTON, 2000)

O muçulmano xiita constrói seu território e sua identidade para além do tempo em que a Ashura é celebrada. É um ato cotidiano que permite a outro grupo interpretá-los. A partir desses propósitos, alguns geógrafos elaboraram modelos sobre as maneiras de se construir essa identidade coletiva. A concepção situacional e relacional de identidade percebe os membros de um grupo como os próprios atores que se atribuem uma significação, em função da situação relacional em que se encontram, visto que é no interior das trocas sociais que a identidade se constrói e reconstrói continuamente.

A respeito desse assunto, $\mathrm{o}$ sociólogo Goffman (1880) reforça o argumento de que a identidade de um determinado indivíduo é construída a partir de parâmetros e expectativas estabelecidas pela sociedade. São os ambientes sociais que determinam as categorias de pessoas que neles podem ser encontradas. Cabe incluir a ideia que essas categorias são encontradas em determinados territórios, que por sua vez, emanam dos grupos sociais. Esta íntima relação entre grupo social e território é defendida por alguns 
geógrafos culturais, que acrescentam a dimensão espacial à formação identitária.

Strauss, teórico expoente e fundador do estruturalismo francês, reteve muito bem a ideia de inconsciente coletivo à antropologia, que pode ser um aporte complementar à ideia de identidade, tendo em vista que a investigação de invariantes nos comportamentos e a noção de afastamento de consciência do sujeito falante, prioriza os fenômenos inconscientes da estrutura, e nos remete ao ser, falar e sentir sem necessariamente racionalizar sobre o fenômeno ou a prática. Dentro desse pensamento teórico, se encerra a ideia de que a identidade obedece a um inconsciente coletivo, marcadamente coeso devido à identidade do grupo. Os indivíduos se adequam, se reúnem e se sensibilizam, demarcando seus territórios por um processo contínuo de pertencimento afetivo. Quando se observa o objetivo do trabalho de Levi-Strauss, percebe-se que seja por meio da análise das estruturas de parentesco, dos mitos, da culinária, da religião ou das artes, a intenção é sempre chegar às estruturas inconscientes que dão origem aos fenômenos sociais. Para ele a sociedade naturalmente se exprime simbolicamente em seus costumes e instituições, e individualmente as condutas jamais serão simbólicas por elas mesmas. (FRÓES, 2013, p.37).
Nesta tentativa de aproximar a antropologia da psicanálise, Strauss mergulha nas particularidades do coletivo e dos grupos, os corolários sociais desses agrupamentos de indivíduos podem ser analisados no prefácio que escreveu para a coletânea Ensaios sobre a Dádiva de 1950 para o sociólogo e antropólogo Marcel Mauss, onde delineia todo pensamento estruturalista e traz a ideia principal de que entende que a formulação psicológica não passa da tradução de uma estrutura sociológica para o plano do psiquismo individual.

$$
\text { CORRÊA, A.M. e }
$$
BONNEMAISON (2006, 2012), atribuem ao grupo social a construção do território através do simbolismo construído no espaço vivido. Esta perspectiva humanista vem de encontro a uma necessidade apontada por HAESBART (2006) que valoriza o processo humano de produção simbólica, priorizando a dimensão ainda mais subjetiva, para minimizar uma rigidez no estudo do território.

O geossímbolo pode ser um lugar, um itinerário, uma extensão que, por razões religiosas, políticas ou culturais, aos olhos de certas pessoas e grupos étnicos assume uma dimensão simbólica que os fortalecem em sua identidade

ESPAÇO E CULTURA, UERJ, RJ, N. 37, P.26-53, JAN./JUN. DE 2015 http://www.e-publicacoes.uerj.br/index.php/espacoecultura/ 
(BONNEMAISON apud

CÔRREA,2002 p. 99109).

A territorialidade islâmica xiita é criada através do ritual religioso do luto. Mauss é um expoente profícuo da ideia de multicausalidade dos fenômenos sociais, admitindo, com isso, que haja uma tessitura de causas que moldam o indivíduo. Este, por sua vez, é totalmente influenciado e estruturado psicologicamente pelo seu meio. Estabelece uma conexão de fatores psicológicos e sociais, ou fatores internos e externos e constrói a ideia de que o indivíduo possui um exterior que molda e um interior que assimila. Perceber essa relação indivíduo e sociedade de uma forma integrada, sendo esse indivíduo influenciado, nos níveis mais profundos, pela coletividade, vai complexificar essas relações, percebendo a multicausalidade e a conectividade dos fenômenos. Mauss vai perceber o indivíduo como parte integrante do todo social em que se encontra, e que o mesmo vai refletir nas suas formas mais profundas e corriqueiras as construções sociais e estruturas que perpassam aquele determinado grupo. Retornando à Lévi-Strauss : "a expressão da cultura do grupo, determinam atitudes individuais duráveis" e que para Marcel Mauss "a formulação psicológica

não é senão uma tradução, no plano do psiquismo individual, de uma estrutura propriamente sociológica" (2003, p.16).

A predominância do social sobre o individual não significa $\mathrm{o}$ descarte permanente do último, esse só pode ser concebido encarnado numa experiência individual, pois seu caráter é tridimensional: sociológico, histórico e fisiopsicológico. Somente num indivíduo se concretizam essas três dimensões. (FRÓES, 2013, p.37)

Algumas ideias se complementam e ajudam a compreender a constituição do território e a relação deste com o indivíduo. Se, de acordo com Bonnemaison, a cultura cria um território, é necessário que a manutenção deste lugar reflita as práticas sociais internalizadas e que regem determinada sociedade. Este território, portanto, será capaz de moldar o indivíduo de maneira complexa e indelével de tal maneira que, caso ele seja retirado de seu território e transferido para qualquer outro espaço, haja uma identificação deste indivíduo, que sem pares e sem nenhuma paisagem característica, possa em decorrência das marcas coletivas, ser reconhecido. 
Podemos então complementar a

ideia de Bonnemaison, agregando a possibilidade de que através de uma cultura típica de luto o território se estabeleça, e de Mauss, onde a expressão dessa cultura seja capaz de guiar as atitudes individuais de maneira contínua e indelével. Desta maneira, caso eu retire o indivíduo do seu território, que no caso seria a Mesquita em plena hierofania, eu manteria a cultura ativa, de maneira que eu pudesse identificálo. O território seria uma consequência da prática cultural, mas não a condição para sua permanência. Isso corrobora a existência da identidade individual e do sentimento de pertencimento, independente de onde esse indivíduo possa estar inserido. Desta maneira, posso me referir a um território-matriz, definido como um lugar principal, de onde emana permanentemente uma essência divina que transcende a necessidade da presença física no temporitual e é capaz de normatizar o comportamento do homem religioso na vida profana. A preocupação com a identidade é de suma importância para o muçulmano xiita já que ele está inserido em uma minoria que detém na história secular, ou seja, não se apoia em nenhum mito, a continuidade do grupo.

Em sua análise, Claude Raffestin (1993) considera que a "territorialidade aparece então como constituída de relações mediatizadas, simétricas ou dissimétricas com a exterioridade",

Com base na fenomenologia, Werther Holzer (1997) constrói outras perspectivas na definição de território, apresentando os limites do conceito construído por Robert Sack. O primeiro limite é o de que a noção de poder desenvolvida por Sack exclui a possibilidade de grupos com outras estruturas de organização, como por exemplo, os nômades, estes perdem o direito de possuírem territorialidade. $\mathrm{O}$ segundo é o de que a territorialidade enquanto processo social não remete diretamente a uma área geográfica onde se desenvolve tal processo. Holzer demonstra que existem possibilidades de constituição de territórios fora de uma ordem planejada por quem detém o poder político ou econômico. Argumenta que o território pode ser visto como um conjunto de lugares, onde se desenvolvem laços afetivos e de identidade cultural de um determinado grupo social, que o território não precisa ser necessariamente fechado a partir de uma delimitação rígida de fronteiras.

Esta reflexão abre um precedente para que se considere a terra imaginalis Karbala como um território móvel e subjetivo. A territorialidade que criada na 
Mesquita é uma tentativa de influenciar e delimitar os indivíduos dentro de um espectro de comportamento ao mesmo tempo que o inserem em uma classificação identitária. Através de uma conexão espaçotemporal a outros lugares, este território é criado fora de um controle político ou econômico, capaz, no entanto, de gerar normatividade. Não há uma ordem planejada nessa construção territorial que poderá ser reconstruída em um tempo sagrado, suspenso e separado do tempo Khronos.

Eliade diz que:

"Consistindo o rito
sempre na repetição de
um gesto arquetípico
efetuado in illo tempore
pelos antepassados e
pelos deuses, procura-se
"onticizar", por
intermédio da hierofania,
os atos mais banais e
mais insignificantes. O
rito coincide por sua
repetição, com o seu
"arquétipo", sendo o
tempo profano abolido."
(ELIADE, 2008).

A ideia do autor acima vincula o rito à existência do tempo sagrado. Partindo dessa constatação poder-se-ia ampliar a ideia de Eliade acrescentando que os atos banais e insignificantes sacralizados por meio da hierofania podem ainda ser capazes de demarcar identidades se forem vinculados ao um território-matriz, que emana permanentemente uma luz e uma orientação subjetiva para além do espaço sagrado. O tempo profano é abolido no momento do rito, quando se tenta alçar ao arquétipo, no entanto, no exemplo islâmico, retorna com mais frequência devido ao território-matriz que sacraliza os atos banais e insignificantes mesmo quando não se está no tempo sagrado. A ligação ao território-matriz de Karbala faz com que os fiéis tenham seu cotidiano religioso e profano influenciados por este território que extrapola as fronteiras da Mesquita durante o ritual de Ashura. Esta tentativa de releitura do território islâmico está além da apropriação e valorização simbólica do lugar vivido, prioriza a dimensão ainda mais subjetiva, para minimizar esta rigidez no estudo do território. (HAESBART, 2006).

O uso diário de cores escuras na indumentária feminina bem como as $d u^{\prime} a s^{10}$ repetidas nos atos cotidianos não se inserem em nenhum tempo ritual. É o territóriomatriz que mantém a cultura islâmica xiita viva e desvincula a identidade do homem à necessidade da presença no território religioso.

Essa performance, totalmente peculiar à vertente xiita, pode ser analisada como um espetáculo. Guardando as devidas proporções e a natureza religiosa, e portanto, ideológica das performances, pode-se aludir ao conceito de Goffman 
(2006) que define performance como toda e qualquer atividade individual de um participante em uma determinada ocasião, e que serve para influenciar sob todas as formas os indivíduos à volta. Os observadores e os outros participantes seriam auxiliares e influenciariam no decorrer do ato performático. Isso significa inferir, que durante a observação participante, o pesquisador influencia na intensidade e nos contornos do que é visto. Por um lado é um desafio metodológico conseguir discernir as diferenças de atuação em diferentes situações, com ou sem a presença de "externos", por outro lado, essa variação deverá também ser um dado a ser levado em conta. Não há duas atuações iguais, portanto, a presença do pesquisador influencia, mas não determina como será a atuação. Nesse sentido, e de acordo com o autor, a partir da observação, podemos chegar à descobrir e analisar os papéis sociais, definidos por ele como:

"uma relação social
advinda de uma
encenação de direitos e
deveres de um certo
status, envolvendo mais
de um papel em diferentes
ocasiões."

Embora Goffman, se refira os papeis societários do cotidiano, a definição de performance como uma atuação para ser observada, variável e suscetível a fatores externos, é perfeitamente compreensível se analisada como um quesito indispensável de um espetáculo religioso.

Schechner (2006) melhor explica o ato performático quando utiliza o termo comportamento restaurado. Ele faz uma comparação a um cineasta defronte a um negativo, no qual poderia observar cada cena como uma unidade independente e separá-la do conjunto. Essas unidades podem ser rearranjadas, justapostas e mudadas na sua ordem, permitindo que o indivíduo repita seus atos ou reinterprete esses extratos comportamentais. Ainda que haja uma lógica sistêmica, seria o manejo e o controle sobre a ação. Ou então nas palavras do autor: "porções recombinadas de comportamentos previamente vivenciados" (2006). Isto exemplifica de maneira bem nítida a capacidade que $o$ xiita tem de evocar o ato elocutório que desencadeia uma ação específica. É o manejo da ação, da performance intencional e controlada. Ainda assim, o comportamento restaurado pode-se dividir em duas subcategorias: o comportamento restaurado de longa duração e o comportamento restaurado de curta duração. O primeiro representado pelos ritos, o segundo representado por gestos banais ou cotidianos, como o acenar de um adeus. Cabe ainda ressaltar, que o comportamento restaurado de curta duração, para o xiita, é também um ritual se intencionalmente direcionado a um gesto de lembrança ao martírio, como beber água 
ou comer, gestos simples que contêm carga simbólica e podem se transformar em um ritual quando há a intenção da adoração e da ligação com o sagrado.

Para facilitar o entendimento da Ashura como uma performance que visa a um espetáculo peculiar, podemos, por fim, fazer uma oposição profícua entre espetáculo e intimidade. Neste binômio em oposição direta pode-se compreender o conceito de espetáculo dentro do xiismo. Portanto, vejamos que DA MATTA apud LEMOS (2014), define intimidade como um refúgio e proteção contra olhares estrangeiros e não familiares, pois cada espaço possui sua própria lógica, que difere substancialmente das demais. Lemos (2014), ainda nos diz que a relação da religião com a intimidade sempre foi bastante complexa, haja vista, sua condição de elemento estruturante da sociedade, apresenta como uma parte do conteúdo que compõe a intimidade. Nesse sentido, enquanto sistema de símbolos, ela age desde dentro, definindo o que seja a própria intimidade. No entanto, ela também trabalha por fora, enquanto elemento estruturado e objetivado na sociedade, normatizando e controlando ou liberalizando a intimidade. Essas duas dimensões agem de forma sistêmica.

Portanto, observa-se que o Islam xiita compartimentaliza o público e o privado de forma contundente. O espetáculo de Ashura busca publicizar a dor, evocar a terra sagrada e fazê-la conhecida ante olhares estrangeiros e externos. O cotidiano xiita, sempre ligado às normatizações de uma território-matriz, externalizam diariamente sua identidade através do simbolismo material. O privado, a intimidade, é reservado a uma parte da religião, que estrutura a relação direta do devoto com Deus. Pode-se afirmar, que na maior parte das vezes, o público, o notório, a norma observável, o simbolismo materializado no ato performático, marcam a ação social xiita.

Em São Paulo, a Ashura é comemorada de acordo com o calendário islâmico, lunar e, portanto, móvel, e representa principalmente uma identidade religiosa, minoritária, no entanto, muito presente e ativa nas celebrações sociais. Participar da preparação dos alimentos no período de Ashura, sua distribuição, comparecer aos 10 dias sem ausências injustificadas, bem como participar das elegias (mulheres) ta'ziyah e das teatralizações - tatbir (homens), confere capital simbólico (BORDIEU, 2000) aos indivíduos, demonstrando piedade e observância religiosa. Portanto, ainda cabem muitas análises de interesse geográfico a este fenômeno religioso, expoente físico de rituais identitários, bem como as migrações e adaptações espaciais entre Karbala-São Paulo.

As particularidades observadas no objeto de pesquisa contribuíram para a compreensão de que a apropriação do conceito de território é passível de 
adaptações e pode modificar-se de acordo com a natureza da sua origem, com a capacidade de mobilidade e com a intensidade da dependência adjacente com que se relaciona com a hierópolis que dá sentido e forma ao ritual de construção.

Identifica-se a contrução do território islâmico na Mesquita do Brás, na cidade de São Paulo, durante as celebrações de Ashura e nas husseynias circundantes ao pólo hierofânico que se espraiam pelo Brasil. Para que esta construção territorial ocorra, há a necessidade de um aporte emocional coletivo, orquestrado hierarquicamente e que demarcam as identidades sociais. Nesse mesmo tempo, identifica-se paralelamente, de maneira concomitante, a construção de um território onde não há participação coletiva. Seria uma segunda tipologia, que de maneira alguma anularia a primeira, já que ambas convergem para uma origem comum, a hierópolis Karbala. A construção desse território matriz apresenta-se como independente do ritual de construção e da hierofania. Portanto, possui valor e força emanente, não cessando seu poder e abrangência, diferindo apenas no tempo em que se observa a manifestação do sagrado. Quando se observa o cotidiano do muçulmano xiita, constata-se que o sagrado pode se manifestar no meio profano de maneira pontual e intermitente. A ideia do tempo primordial que permite um eterno retorno à ontologia e culmina com a imersão no sagrado, através da ligação com
Karbala, é desmembrada no empírico. O cotidiano do homem religioso xiita apresenta um gestual e um conjunto de atos elocutórios que podem se travestir de sacralidade se houver a intenção da adoração. Isso nos leva a concluir, como observado no item c, que há uma dependência em alto grau de intensidade com a hierópolis Karbala.

A frequência com que se observa a ligação do homem religioso com sua hierópolis e, neste caso, com o sagrado, deixa de ser cíclica e marcadamente temporal para se tornar frequente. Neste caso, Raffestin (1993, p.193) considera que a

"territorialidade aparece
então como constituída
de relações mediatizadas,
simétricas ou
dissimétricas com a
exterioridade".

Incluindo elementos de identidade, exclusividade e de limite. Essa ideia reforça a constatação de que a relação individual do homem religioso com sua fé é exclusiva daquele indivíduo. Isso se aplica a segunda tipologia do conceito de território, quando há um padrão normatizador advindo da terra sagrada. No caso do grupo pesquisado, a observação do gestual e dos ritos no cotidiano foi mediatizada por elementos simbólicos (indumentária e utilização de 
artefatos e discursos) que são exteriorizados e que ao mesmo tempo, desempenham a dupla função ora de limitar seu espaço, ora de demarcar sua territorialidade. A identidade advém desta limitação exterior que é capaz de identificá-lo enquanto pertencente àquele grupo. $\mathrm{O}$ protótipo do solo sagrado seria um arché capaz de condensar simbolicamente o significante da identidade cultural do grupo religioso. Os territórios, portanto, seriam o produto do tripé solo-ritual- identidade.

Apesar da tentativa de descrever as ideias suscitadas acerca das diferentes interpretações e tipologias de território islâmico nessa pesquisa, o ponto comum, no entanto, e que se pôde constatar, é que tanto a terra imaginalis, móvel e cíclica, base fulgral do território construído na Mesquita do Brás, tanto a ideia de território matriz, pontual e normatizador, denotam uma identidade particular que os caracteriza e os define como muçulmanos xiitas. Podemos então corroborar nesta pesquisa a ideia de Bonnemaison (2005), agregando a possibilidade de que através de uma cultura típica de luto, característica de uma etnia, o território se estabeleça, e de Mauss (2005), onde a expressão dessa cultura seja capaz de guiar as atitudes individuais de maneira contínua e indelével. Ainda de acordo com Bonnemaison, este trabalho cumpre com o objetivo da Geografia Cultural que afirma que as questões acerca do território não consistem em apreender o fato cultural nele mesmo, mas em definir territórios reveladores de etnias e culturas (BONNEMAISON apud CORRÊA. A, M. 2006, p. 56).

Portanto, ficam abertas as portas para a continuação desse aprofundamento conceitual. As infinitas possibilidades de apropriação do conceito nos permite não concluir mas direcionar as pesquisas para o aprofundamento do conceito de território, visto que as possibilidades de reinterpretar os conceitos geográficos á luz dos fenômenos religiosos são infinitas.

\section{Considerações Finais}

Os geossímbolos exponenciados em sua representatividade como alicerce e estandarte de um aparato ideológico, ganham foco e relevância. Através dessa nova construção territorial, apoiada no simbolismo e em sua materialidade, observam-se novos desdobramentos de grande impacto social, como as construções de novas identidades e a manutenção de uma comunidade religiosa de grande expressão demográfica, e que hoje, compõe a sociedade brasileira em contínuo processo de assimilação. As conclusões parciais observadas até então, nos induzem à continuidade da pesquisa e á constatação inequívoca da plasticidade profícua e necessária às ciências humanas em geral, e especificamente, à Geografia Cultural, que 
busca analisar as diversas leituras acerca do território, suas apropriações e a origem de novos símbolos, sagrados ou profanos mas

Nota

${ }^{1}$ Cientista Social e Pedagoga. Doutoranda em Geografia pela Universidade do Estado do Rio de Janeiro (PPGEO/UERJ). Mestre em Geografia pela Universidade do Estado do Rio de Janeiro (PPGEO/UERJ). Pesquisadora do Grupo de Pesquisa Brasil-Irã da UFRJ e do NEPEC (Núcleo de Estudos e Pesquisas sobre Espaço e Cultura) na UERJ. Email: kary_arc@yahoo.com.br

2 Abreviatura de الـ لـ بـان ية الــ قاومة أفواج. A transliteração é: Afwâj al Muqâwmat alLubnâniyya, ou apenas أمل حركة, com transliteração é: Harakat Amal, ou literalmente Movimento AMAL. É uma abreviação de Batalhão da Resistência Libanesa, que significa: esperança.

${ }^{3}$ No sentido de pregar e exercer normas contrárias às pregadas pelo Islam, apesar dos governantes proclamarem-se muçulmanos ${ }^{4}$ Nação islâmica.

5 Retirado de www.mesquitadobras.org.br/?op=33 em $12 / 03 / 2014$

6 Celebração.

${ }^{7}$ Disponível em: http://karbala.blog.com/2012/01/27/a-origemdo-nome-karbala/

${ }^{8}$ Lei islâmica.

${ }^{9}$ Pedra de pequenas dimensões feita a partir da Terra de Karbala que representa em pequena escala essa conexão da Terra mater com o ritual que reconstrói simbolicamente a paisagem de Karbala.

${ }^{10}$ Preces. capazes, ambos, de carregar a origem e o devir de uma cultura religiosa .

Referências Bibliográficas

AGHAIE, K. The Martyrs of Karbala: Shi'i Symbols and Rituals in Modern Iran. Seattle: University of Washington Press, 2004.

The Women of Karbala: Ritual Performances ans Symbolic Discourses in Modern Shi'I Islam. Austin: University os Texas Press, 2005

ARROYO, K. Ashura: o ritual de construção do luto e encenação na cidade de São Paulo. CADERNau (Caderno do Núcleo de Análises Urbanas) v.7, nº 1 , Rio Grande, 2014, p. 149-161

BONNEMAISON,J. Culture and Space: Conceiving a New Geography. London: I.B Tauris e Co Lt, 2005

Viagem em torno do Território. In: CÔRREA, ROSENDAHL. Geografia Cultural: um século. Rio de Janeiro: EdUERJ, 2002

BORDIEU, P. O Poder Simbólico. São Paulo: Bertrand Brasil, 2000

CLAVAL. P. Espaço e Poder. São Paulo: Zahar, 1979 1995 Ethnogéographies. Paris: L`Harnattan,

CORREA, R, L. Monumentos, Política e Espaço. In:Scripta Nova - Revista Electrónica de Geografia Y Ciências Sociales. Barcelona, v. IX, no ${ }^{\circ}$ 183, 15 de febrero de 2005

Redes geográficas: reflexões sobre um tema persistente. In: Revista Cidades. São Paulo, v.16, n 9 , junho de 2011. p199-218

CÔRREA, R.L, ROSENDAHL, Z. Geografia Cultural: Apresentando uma Antologia. In: Côrrea, R.L, Rosendahl, Z (org.) Geografia Cultural - Uma Antologia. Rio de Janeiro: EdUERJ, 2012

Religião, Identidade e Território. Rio de Janeiro: EdUERJ, 2001

(org.) Geografia

Cultural: Uma Antologia. Vol I. Rio de Janeiro: EdUERJ, 2012 
CORREA, A.M. O terreiro de candomblé: uma análise sob a perspectivada geografia cultural. Textos escolhidos de cultura e arte populares. Rio de Janeiro, v. 3, no 1, junho de 2006. p 51-62

COSGROVE, D. A Geografia está em toda parte: cultura e simbolismo nas paisagens humanas. In: Côrrea, R.L, Rosendahl, Z (org.) Geografia Cultural Uma Antologia. Rio de Janeiro: EdUERJ, 2012

Em direção a uma geografia cultural radical: problemas da teoria. Espaço e cultura. Rio de Janeiro, n. 5, dez. 1998, p.27

DEHAENE, M. DE CAUTER, L. Public Space in a Postcivil Society. New York: Routledge, 2008

DURKHEIM, E. As regras do método sociológico. In: Metodologia das Ciências Humanas. São Paulo: UNESP,2001, p. 29-51.

As formas elementares da vida religiosa. Curitiba: EP, 1989

ELIADE, M. O Sagrado e o Profano. São Paulo: Martins Fontes, 1992

Tradado de História das Religiões. São Paulo: Martins Fontes, 2008

FICKELER, PAUL. Questões Fundamentais na geografia da religião. Espaço e Cultura - Edição Comemorativa. Rio de Janeiro: UERJ, NEPE, 2008

FROES, H. O conceito de inconsciente em LeviStrauss revisitado. In: Pólemos, v.2, nº 4, Brasília, dezembro 2013

GEERTZ, C. La interpretación de lãs culturas. Barcelona: Gedisa Editorial, 2000

.O saber local: novos ensaios em antropologia interpretativa. Trad: Vera Mello Joscelyne. Petrópolis: Vozes, 1997

Nova luz sobre a antropologia. Rio de Janeiro: Jorge Zahar editor, 2001

Negara: o estado-teatro no século XIX.

Rio de Janeiro: Bertrand Brasil, 1991

Centros, Reis e Carisma: reflexões sobre o simbolismo do poder. In: Geertz. Osaber local.

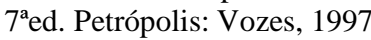

GOFFMAN, E. Estigma-Notas sobre a Manipulação da Identidade deteriorada. Rio de Janeiro: Zahar Editores, 1980.

HAESBART, R. Identidades Territoriais. In: Geografia Cultural: Uma antologia. Volume II. Rio de Janeiro: EdUERJ, 2013
Paulo: Contexto, 2002

O mito da desterritorialização: do fim dos territórios à multiterritorialidade. Rio de Janeiro: Bertrand Brasil, 2006.

HALL, S. Da diáspora: identidades e mediações culturais. Belo Horizonte: Editora UFMG, 2006

A Identidade cultural na pósmodernidade. Rio de Janeiro: DP\&A, 2005

LAPASSADE, G. $L^{\prime}$ Éthnosociologie. Paris: Méridiens Klincksieck, 1991

LEMOS, C. T. Intimidade: entre o confessionário e a religião do espetáculo. In: A religião entre o Espetáculo e a Intimidade. Goiás: PUC -GO, 2014

Árabes no Rio de Janeiro: uma identidade plural. Rio de Janeiro: Cidade Viva, 2010

PINTO, Paulo. G. Islã: Religião e Civilização - Uma abordagem Antropológica. Aparecida, SP: Santuário, 2010

Mercados de Devoção: Consumo e Identidades Religiosas nos Santuários de Peregrinação Xiita na Síria”. In: Cultura, Consumo e Identidade. Lívia Barbosa e Collin Campbell (org.)Rio de Janeiro: Editora FGV, 2006

KHAZRAJI T. A Revolução do Imam Hussein: Motivos, Fatos e Resultados. São Paulo: Arresala, 2008

MAHMOOD, S. Politics of Piety. Princeton: Princeton University Press, 2004

MARTINS, P.H. A sociologia de Marcel Mauss: Dádiva, simbolismo e associação . In: Revista Crítica de Ciências Sociais, n. 73, Universidade de Coimbra, Coimbra, agosto de 2005, p. 45-66.

MERVIN, Sabrina. Histoire De L'Islam: Fondementes Et Doctrines. Paris: Flammarion, 2001

MUZZAFAR, M. As crenças islâmicas. São Paulo: Arresala, 2009

NORTON, W. Cultural Geography: Themes, Concepts, Analysis. Oxford: Oxford University Press, 2000

RAFFESTIN, C. Por uma geografia do poder. São Paulo: Ática, 1993

ROSENDAHL, Zeny. Espaço e Religião: uma abordagem geográfica. Rio de Janeiro: UERJ, NEPEC, 1996 
Hierópolis: $O$ Sagrado $E$ O Urbano. Rio de Janeiro: EdUERJ, 1999

\section{Espaço, Política e Religião. In:} Geografia Cultural: Uma antologia. Volume II. Rio de Janeiro: EdUERJ, 2013

Território e territorialidade: uma proposta geográfica para o estudo da religião. In: Geografia Cultural: Uma antologia. Volume II. Rio de Janeiro: EdUERJ, 2013

SAUER, Carl O. Geografia cultural. Espaço e cultura. Rio de Janeiro, n. 3,dez. 1996, p. 4.

SCHECHNER, Richard. What is performance. In: Performance studies: an introduccion, second edition. New York \& London: Routledge, p. 28-51, 2006

SOUZA, M. L. de. O território: sobre espaço e poder, autonomia e desenvolvimento. In: Castro, I. E. et al. Geografia: conceitos e temas. Rio de Janeiro: Bertrand, 1995
STRAUSS, L. Raça e História. Paris: UNESCO, 1950

SUBHANI, Y. La Historia del Profeta del Islam, Muhammad (BP). Qom: Fundación Cultural Oriente, 2006

TUAN, Yi-Fu. Espaço e lugar: a perspectiva da experiência. São Paulo: Dife,1983.

Topofilia - Um estudo da percepção, atitudes $e$ valores do meio ambiente. Londrina: EDUEL, 2012

TRUZZI, Oswaldo Mário Serra. De mascates a Doutores: Sírios e libaneses em São Paulo. São Paulo: HICITEC, 1997

VIDAL DE LA BLACHE, P. As características próprias da Geografia.In: ChristofolettiI, Antônio (Org.). Perspectivas da Geografia. São Paulo: Difel, 1995

WEBER, M. The Sociology of Religion. Beacon Press, 1993

Ensaios de Sociologia. Ed.

Guanabara: Rio de Janeiro, 1981. 
CONSTRUCTION OF A RELIGIOUS LAND MOBILE IN BRAZIL: ISLAM, IDENTITIES

AND SYMBOLISM

\begin{abstract}
IN THIS ARTICLE AN ISLAMIC RELIGIOUS RITUAL WITH RELEVANT PARTICULARS TO THE FIELD OF GEOGRAPHICAL SCIENCE WAS ANALYZED. THE RESEARCH SOUGHT TO UNDERSTAND HOW THE SACRED MANIFESTS ITSELF IN THEIR TERRITORY, CONSIDERING THE PECULIARITY OF THE RESEARCH OBJECT. FROM THE CONCEPTUAL DEEPENING SCREEN, THE OUTLOOK ON THE MEANING OF TERRITORY, SUPPORTED BY A SOCIO-ANTHROPOLOGICAL BASIS, SEEK TO DESCRIBE, ANALYZE AND CLASSIFY WITHIN THE HUMAN GEOGRAPHY, SPECIFICALLY THE RENEWED CULTURAL GEOGRAPHY, CULTURAL AND RELIGIOUS RITUALISTIC PERFORMANCE OF MAJOR DEMOGRAPHIC EXPRESSIVENESS AND STILL LITTLE KNOWN IN BRAZIL. THEREFORE, KNOWLEDGE OF THIS ISLAMIC RITUAL BRINGS IN A COMPREHENSIVE AND TIMELY MANNER, NEW POSSIBILITIES FOR INTERPRETING THE PLACE AND TERRITORY, EXTENDING ITS MEANING AND PROPOSING NEW WAYS OF APPROPRIATION OF CONCEPTS, AND INTO THE SUBJECTIVITY WITH MOBILE TERRITORIALITY THROUGH THE EARTH IMAGINALIS.
\end{abstract}

KEYWORDS: ISLAMIC TERRITORY, ASHURA RITUAL, IDENTITY 